\title{
Steep-slope threshold switch enabled by pulsed-laser-induced phase transformation
}

Yunkyu Park ${ }^{1)}$, Daseob Yoon ${ }^{1)}$, Keisuke Fukutani ${ }^{2)}$, Roland Stania ${ }^{2)}$ and Junwoo Son ${ }^{1{ }^{*}}$

${ }^{1)}$ Department of Materials Science and Engineering (MSE), Pohang University of Science and Technology (POSTECH), Pohang 37673, Republic of Korea

2) Center for Artificial Low Dimensional Electronic Systems, Institute for Basic Science (IBS), Pohang 37673, Republic of Korea

*jwson@postech.ac.kr 

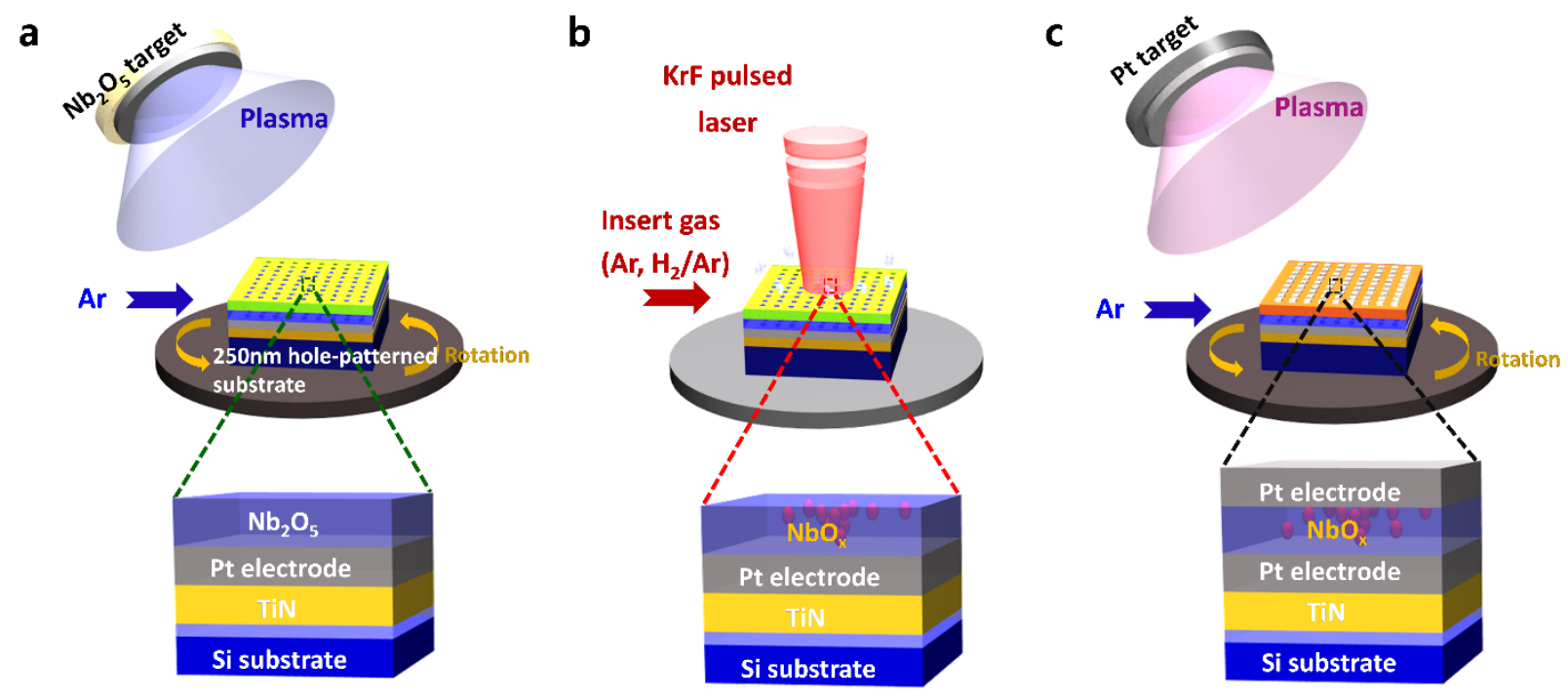

Figure S1 | A schematics of fabrication process for the $\mathrm{NbO}_{2}$-based threshold switch using pulsed laser annealing. a. $40 \sim 50 \mathrm{~nm}$-thick $\mathrm{NbO}_{\mathrm{x}}$ films were deposited on the nano-patterned substrates (Pt/TiN/SiO2/Si) with a 250-nm-diameter hole patterns using $\mathrm{Nb}_{2} \mathrm{O}_{5}$ target $(99.995 \%)$ by rfmagnetron sputtering at room temperature. b. pulsed laser annealing $(\mathrm{KrF}, \lambda \sim 248 \mathrm{~nm}$, energy density $\sim 65 \mathrm{~mJ} / \mathrm{cm}^{2}$ ) was performed on the $\mathrm{Nb}_{2} \mathrm{O}_{5}$ film in the gas-controlled chamber by adjusting number of laser pulses and process environment (pure Ar gas, $1 \sim 5 \% \mathrm{H}_{2} / \mathrm{Ar}$ gas). c. 40 -nm-thick Pt top electrodes were deposited on the as-grown or laser-annealed $\mathrm{NbO}_{\mathrm{x}}$ film to fabricate twoterminal device structure. 

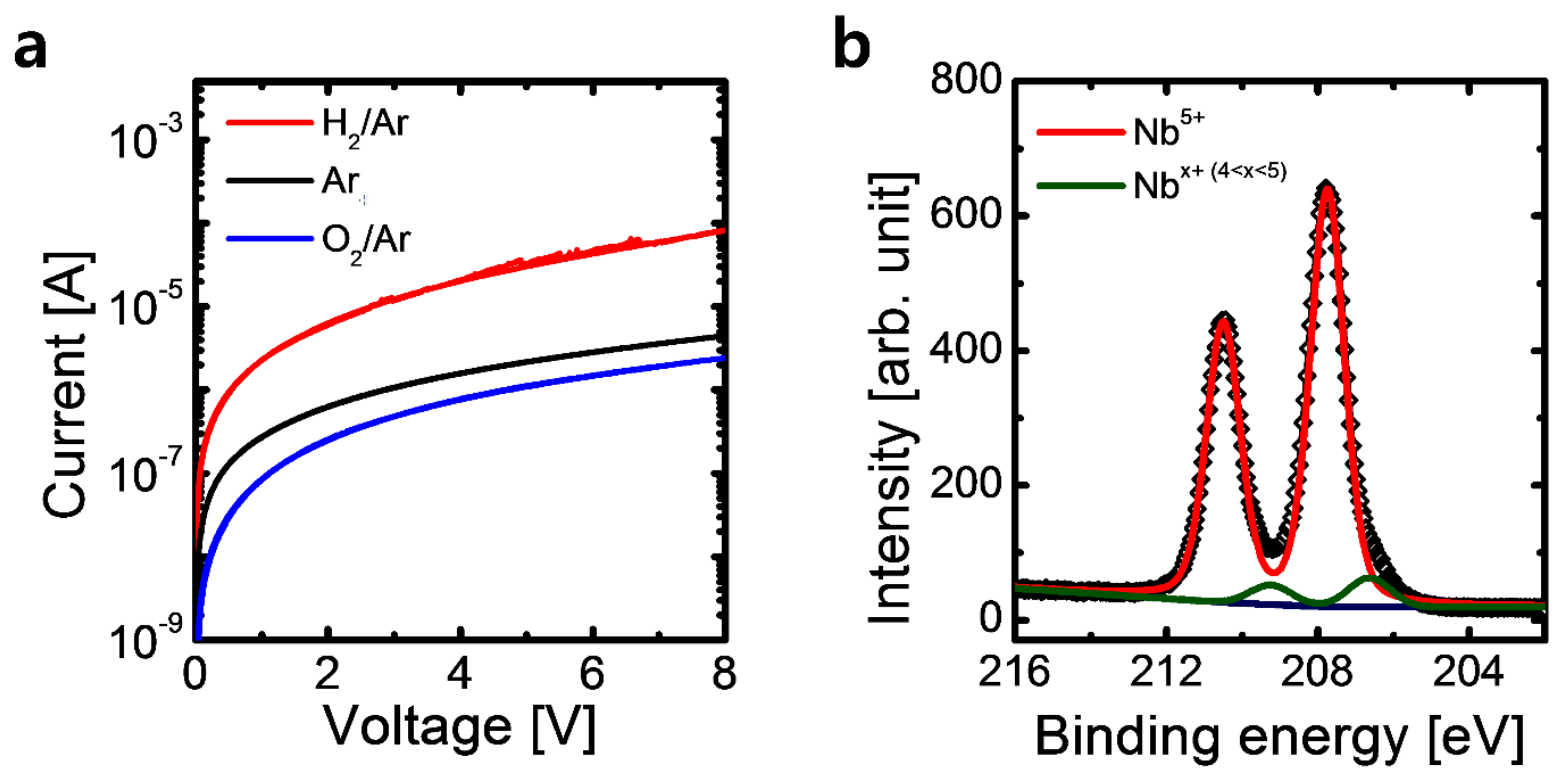

Figure S2 $\mid$ a. current-voltage (I-V) characteristics of two-terminal devices with as-grown $\mathrm{NbO}_{\mathrm{x}}$ films, which were deposited at different growth environment (pure $\mathrm{Ar}, \mathrm{O}_{2} / \mathrm{Ar}$ mixture with $\mathrm{P}\left(\mathrm{O}_{2}\right)$ $=\sim 0.5 \mathrm{mTorr}, \mathrm{H}_{2} / \mathrm{Ar}$ mixture with $\left.\mathrm{P}\left(\mathrm{H}_{2}\right)=\sim 0.5 \mathrm{mTorr}\right)$. The as-grown $\mathrm{NbO}_{\mathrm{x}}$ films grown under $\mathrm{O}_{2} / \mathrm{Ar}$ atmosphere showed the lowest leakage current. b. The XPS spectra of $\mathrm{Nb} 3 \mathrm{~d}$ core-level on the as-grown $\mathrm{NbO}_{x}$ film. Since $\mathrm{Nb}^{5+}$ is thermodynamically stable, as-grown $\mathrm{NbO}_{\mathrm{x}}$ film exhibit amorphous $\mathrm{Nb}_{2} \mathrm{O}_{5}$ phase. 

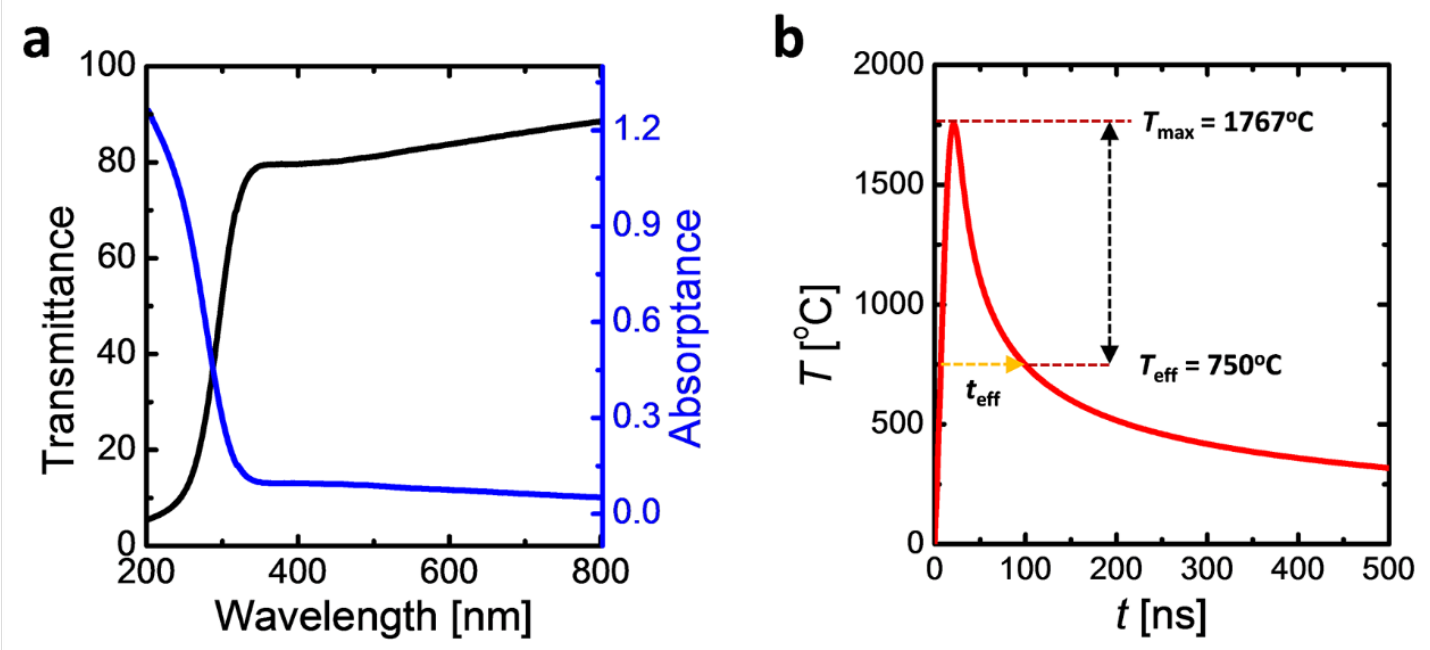

Figure S3 a. Measured transmittance and absorptance spectra of a- $\mathrm{Nb}_{2} \mathrm{O}_{5}$ films and b. timedependent temperature profile under 20ns pulsed laser annealing, which is estimated by using simulation with the mathematical formula of heat diffusion equations. $\mathrm{T}_{\max }, \mathrm{T}_{\text {eff }}$ and $t_{\text {eff }}$ are the maximum temperature, effective temperature and effective time during pulsed laser annealing. 


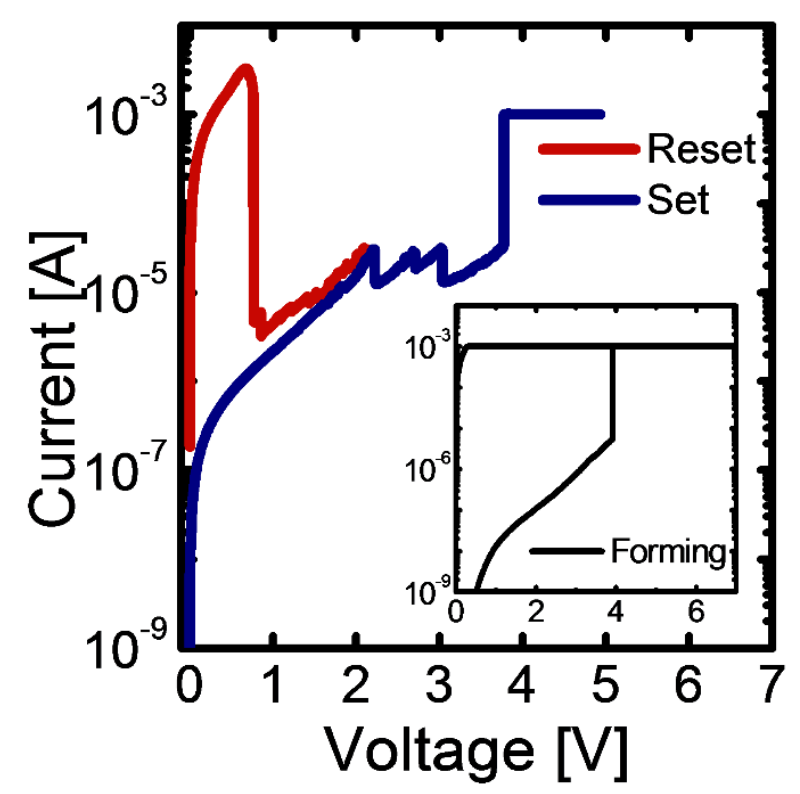

Figure S4 $\mid$ a. current-voltage (I-V) characteristics of the two-terminal $\mathrm{NbO}_{\mathrm{x}}$ devices after 3000 shots of pulsed laser under Ar environment. After initial soft breakdown at $\sim 4.0 \mathrm{~V}$ as a forming process (inset of a), 'reset' process was occurred at $0.7 \mathrm{~V}$ ( $\left.\mathrm{V}_{\text {reset }}\right)$ from low resistance state (LRS) to high resistance state (HRS), and then 'set' process from LRS to HRS was observed at $3.8 \mathrm{~V}\left(\mathrm{~V}_{\text {set }}\right)$ in the subsequent positive sweep. Due to the insufficient forming of oxygen vacancies as a conductive filament after 3000 shots of pulsed laser, the devices requires the electro-forming process for unipolar resistive switching during the initial sweep. 


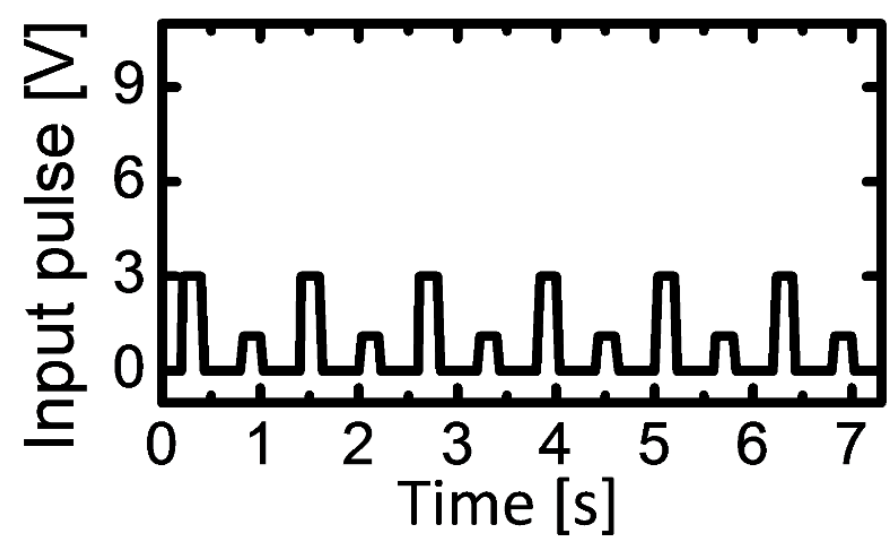

Figure S5 | Alternative input pulses with $3 \mathrm{~V}$ and $1.1 \mathrm{~V}$ voltage amplitude with 1.2 second period. (i.e., primary pulse with $200 \mathrm{~ms}$ pulse width was applied after $200 \mathrm{~ms}$ delay time, and additional pulse with same pulse width (200ms) was applied after $800 \mathrm{~ms}$ delay time). The voltage pulses were applied to the top Pt electrode of two-terminal device. 


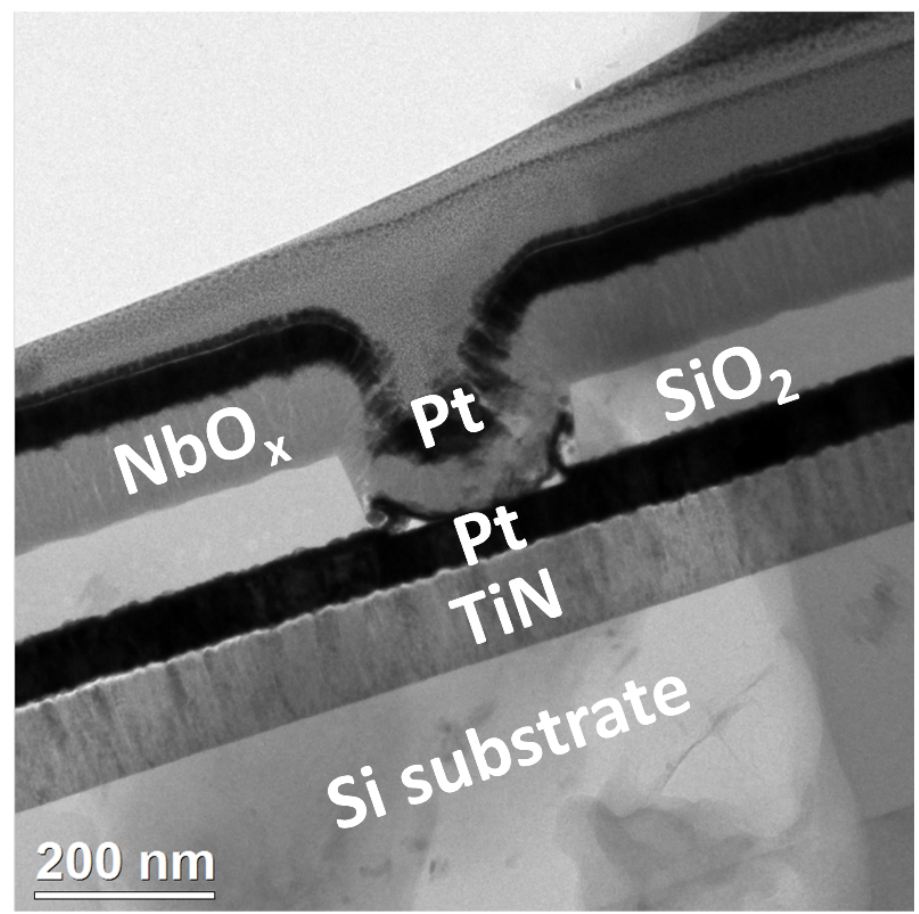

Figure S6 | cross-section HRTEM image of two-terminal device with $\mathrm{NbO}_{\mathrm{x}}$ film on the $250 \mathrm{~nm}$ hole-patterned substrate, 

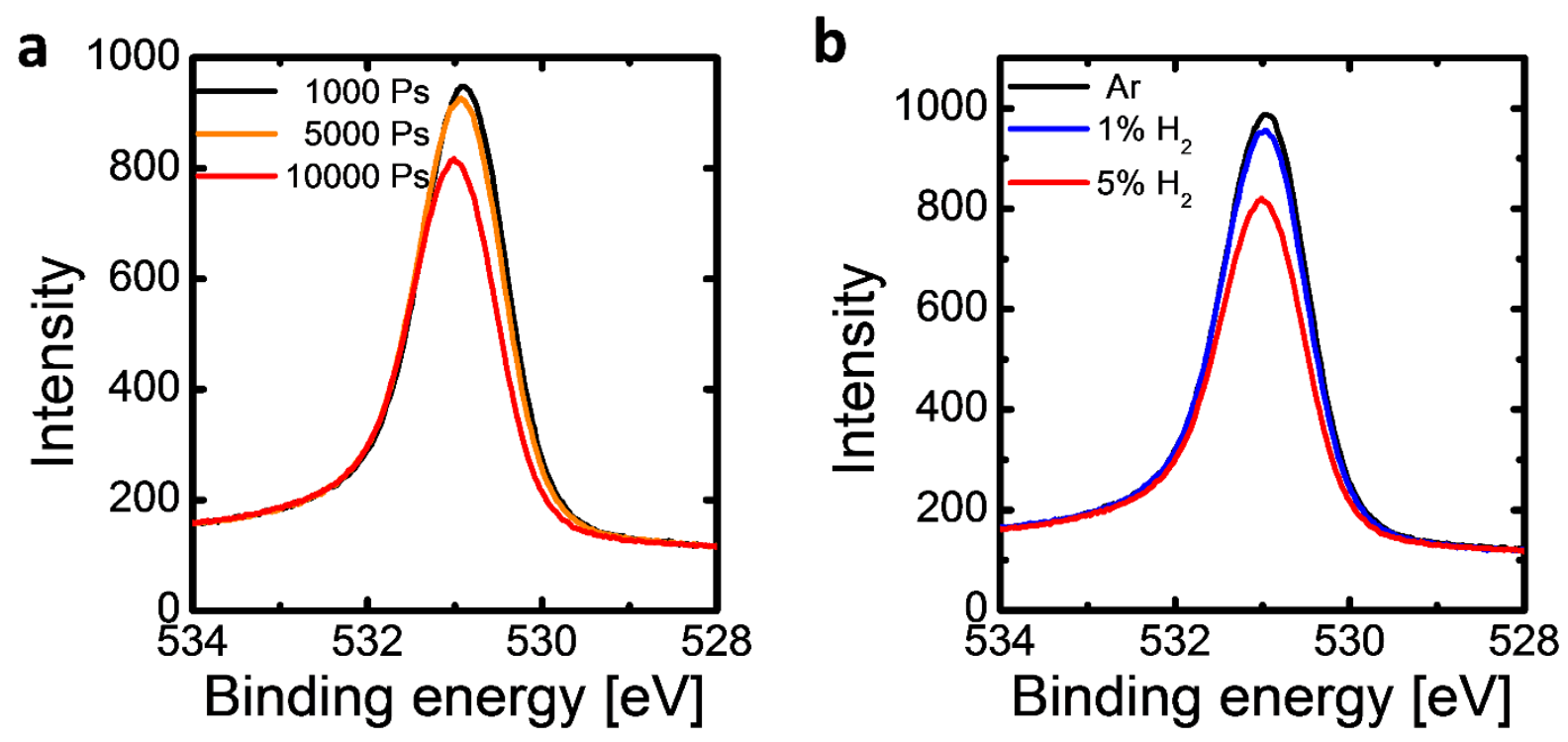

Figure S7 | Raw data of O 1s core-level spectra of laser-annealed $\mathrm{NbO}_{\mathrm{x}}$ films with a. different repetition number of pulsed laser and $\mathbf{b}$. process environment. O 1s core-level peaks was shifted to the higher energy with increasing number of pulsed laser $(530.90 \mathrm{eV}$ at 1000 pulses to 531.01 $\mathrm{eV}$ at 10000 pulses) and more reducing environment (530.96 eV under Ar to $531.01 \mathrm{eV}$ under $5 \%$ $\left.\mathrm{H}_{2} / \mathrm{Ar}\right)$, which represents the more formation of $\mathrm{O}-\mathrm{Nb}^{4+}$ bonding $(531.03 \mathrm{eV})$ than $\mathrm{O}-\mathrm{Nb}^{5+}(530.8$ $\mathrm{eV}$. Moreover, the intensity of $\mathrm{O} 1 \mathrm{~s}$ spectra gradually decreased with increasing the number of pulses and/or the degree of reducing environment. 
Supporting Note $1 \mid$ a quantitative measure of the oxygen contents by the normalized area of

\section{O 1s spectra}

A relatively quantitative measurement of oxygen contents in $\mathrm{NbO}_{\mathrm{x}}$ film are determined based on the $\mathrm{O} 1 \mathrm{~s}$ core-level spectra by normalizing the O1s spectra to the reference. The integrated area of $\mathrm{O}$ 1s spectra, $\mathrm{A}(\mathrm{O} 1 \mathrm{~s})$, is first normalized by the integrated intensity of $\mathrm{Nb} 3 \mathrm{~d}$ valence spectra, $\mathrm{A}(\mathrm{Nb} 3 \mathrm{~d})$, with identical post-treatment. This is done to account for fluctuations in beam intensity at different samples. The fraction of integrated area of $\mathrm{O} 1 \mathrm{~s}$ is normalized by a reference and is related to the oxygen content at the thin film surface.

$$
[0]^{\text {rela.qant. }}=A(01 s)_{\text {norm }}=\frac{A(O 1 s) / A(N b 3 d)}{A(01 s)_{\text {ref }} / A(N b 3 d)_{\text {ref }}}
$$

The reference is set to the sample closest to $\mathrm{Nb}_{2} \mathrm{O}_{5}$ with the least $\mathrm{Nb}^{4+}$ ratio (See Fig 4a), which treated by 1000 laser pulses in $5 \% \mathrm{H}_{2} / \mathrm{Ar}$ environments. 


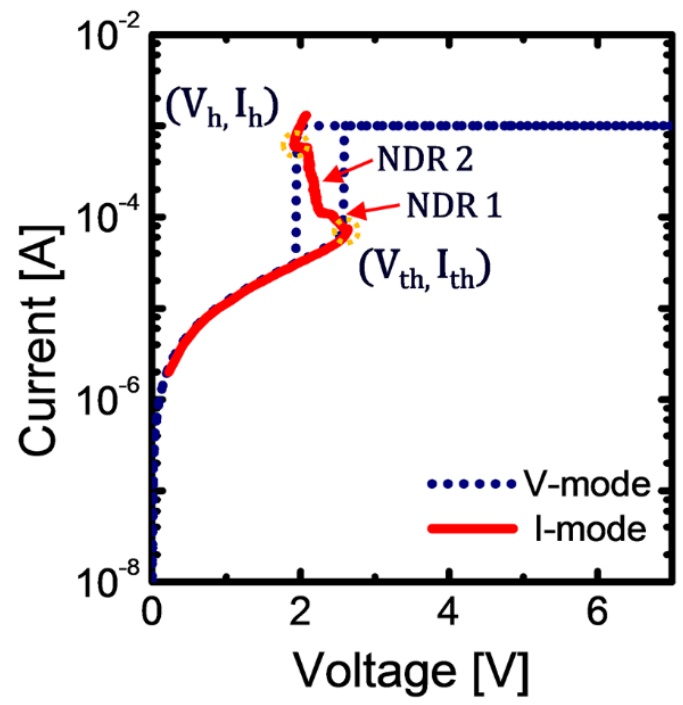

Figure S8 | Voltage (blue) and current (red) controlled I-V characteristics in the laser annealed $\mathrm{NbO}_{2}$ based threshold switches. Multi-NDR was observed during current-driven switching in our laser-annealed $\mathrm{NbO}_{2}$ threshold switches. 